\title{
A atividade de camelô como prática urbana no contexto das cidades
}

\author{
The activity of street vendors as a practice in the urban context
}

Luciano Mendes ${ }^{[0]}$, Neusa Rolita Cavedon ${ }^{[b]}$

[a] Doutor em Administração pela Universidade Federal do Rio Grande do Sul (UFRGS), professor adjunto da Universidade Federal de Mato Grosso do Sul (UFMS), Barretos, SP - Brasil, e-mail: lucianobtos@yahoo.com.br

[b] Doutora em Administração pela Universidade Federal do Rio Grande do Sul (UFRGS), professora associada da Escola de Administração da UFRGS e pesquisadora do CNPq, Porto Alegre, RS - Brasil, e-mail: nrcavedon@ea.ufrgs.br

\section{Resumo}

O objetivo neste ensaio foi analisar a atividade de camelô a partir das discussões e dos conceitos de cidade e território. Essa análise leva em consideração estudos etnográficos desenvolvidos no mercado camelô e, também, os dois deslocamentos propostos, sendo: primeiro o deslocamento da ideia de cidade-conceito para o de práticas urbanas; e, segundo, a desmistificação da lógica estabelecida na reestruturação produtiva, que verifica o funcionamento da atividade de camelô como uma prática marginalizada. Por isso, é necessária uma análise sobre os conceitos de cidade, e o funcionamento e as possibilidades da atividade de camelô no entremeio a esses conceitos, para, no fim deste ensaio, subsidiar algumas implicações sobre a lógica até então estabelecida e que cria pressupostos e preconceitos sobre o funcionamento de tal atividade de comércio. Assim, um primeiro passo será a discussão dos conceitos de cidade e as implicações da atividade de camelô neste entremeio; o segundo passo será um aprofundamento das discussões sobre a cidade na lógica das práticas urbanas, procurando salientar a importância de se observar os microterritórios; o terceiro será a apresentação de estudos etnográficos desenvolvidos no mercado camelô; e, por fim, o quarto passo é uma análise sobre os dados discutidos nesses trabalhos etnográficos, levando em consideração as discussões sobre cidade e território, e permitindo o deslocamento para a ideia de práticas urbanas, bem como a desmistificação da lógica na reestruturação produtiva.

Palavras-chave: Camelô. Cidade. Mercado informal. Território. Prática urbana.

\section{Abstract}

The aim of this paper is to analyze the street vendors activity using the discussions and concepts of city and territory. This analysis takes into account ethnographic studies carried out in the hawker market, as well as the 
proposed two shifts, as follows: the displacement of the idea of city-concept for urban practices, and according to the demystification of the logic established in the restructuring process, which verifies functional street vendors activity marginalized as a practice. This requires an analysis of the concepts of city, as well as operation and possibilities of the street vendor activity in between these concepts, in order to subsidize, at the end of this essay, some implications for the logic previously established and establish assumptions and prejudices about operation of such trading activity. A first step will be discussion of the concepts and implications of city street vendor activity in this inset. The second step will be a deepening of discussions about the city in the logic of urban practices, seeking to emphasize the importance of observing the microterritory. Third will be the presentation of ethnographic studies in the developed peddler market. Finally, the fourth step is an analysis of the ethnographic data discussed in this work, taking into account the discussions of city and territory, allowing the offset to the idea of urban practice, and the demystification of logic in the restructuring process.

Keywords: Street vendor. City. Informal market. Territory. Urban practice.

\section{Introdução}

Com a incursão brasileira à política neoliberal, a partir da década de 1990, ocorreu uma verdadeira reestruturação produtiva. Essa política neoliberal, constituída e disseminada nos países desenvolvidos, produziu o que se poderia chamar de acumulação flexível. Essa acumulação, salienta Harvey (1992), impactou diretamente no mercado de trabalho, gerando categorias como: a subcontratação, as agências de temporários e os autônomos. Essa transformação no mercado de trabalho, de acordo com Harvey (1992), abre duas possibilidades interessantes. A primeira é a possibilidade de uma mão de obra contratada de forma flexível (contrato de curto prazo, trabalho em tempo parcial etc.) que sustenta as novas formas de organização industrial. A segunda é o surgimento de pequenos negócios, muito semelhantes às formas mais antigas de trabalho doméstico, artesanal, familiar e paternalista. Nessa segunda temática, o que está em jogo são novas estratégias de sobrevivência para os desempregados ou discriminados, assim como, em casos específicos, formas organizadas de sonegação de impostos ou a possibilidade de altos lucros no comércio ilegal.

De uma forma ou de outra, o que se observa é o surgimento, cada vez mais central, desses pequenos comércios, seja nos grandes centros ou nas pequenas cidades. A lógica capitalista de acumulação flexível possibilitou também alterações evidentes nas formas de apropriação do espaço urbano. A cidade, enquanto espaço de centralidade da movimentação e ação humana, permite detectar nitidamente a proliferação disso que Harvey (1992) chamou de o surgimento de pequenos negócios.

Nesta linha, a expansão geográfica e a reorganização espacial, na concepção de Harvey (2005), possibilitam ao capitalismo funcionar como sistema econômico político, rumo a um incessante ajuste espacial que permite (re)configurações constantes do espaço urbano, dando novos significados a ideia de cidade. É desse contexto que aparece a cidade dual, proveniente das novas formas de tecnologia informacional que, de um lado, produzem e reproduzem modelos contemporâneos de organização do trabalho e, de outro lado, um grupo cada vez maior de desempregados e de marginalizados.

É dessa cidade dual ou - como prefere chamar Castells (1995) - cidade informacional que aparece a atividade de camelô. Essa atividade é, provavelmente, fruto daquilo que Harvey (1992) chamou de pequenos negócios, muitas vezes conduzidos por esse grupo de desempregados e marginalizados. Nesta linha, é possível deduzir que essas atividades foram constituídas mais como estratégia de sobrevivência do que como atividades voltadas somente para a sonegação de impostos ou possibilidades de altos lucros pelo comércio ilegal. Mas essa análise evidencia formas esquemáticas de apreensão sobre os negócios e estruturas desenvolvidas nas cidades, como modelos generalizáveis a todos os espaços urbanos. Por esse motivo, Certeau (2008) chama essa concepção analítica de cidade-conceito, no sentido mais geral e utópico de manifestação do espaço urbano, que permite generalizações e a existência de uma cidade com formas definidas. 
Na análise de Certeau (2008), essa cidade-conceito aparece sob uma tríplice operação, que congrega a produção do espaço próprio, o estabelecimento de um não tempo ou sistema sincrônico e a constituição de um sujeito universal - no sentido exposto por Hobbes (1997) -, que é a própria cidade. Nesta temática é que se torna possível falar em uma cidade dual, assim como observar tais manifestações por meio de temáticas gerais - e muitas vezes universais - de surgimento de categorias articuladas ao predomínio do sistema capitalista, bem como aquelas categorias marginalizadas. Mas isso tudo apresenta uma cidade com forma definida, racionalizada, pensada em sua constituição quadro a quadro que, muitas vezes, está além das práticas sociais e da dinâmica das cidades.

Seguindo o traçado deixado por Certeau (2008), é necessário deslocar essa ideia de cidade-conceito para as de práticas urbanas, pois observar a cidade a partir das formas definidas impede a compreensão da dinâmica urbana. Isso não quer dizer que essa visão estrutural não seja importante, mas que um olhar sobre as práticas urbanas possibilita maior riqueza na apreensão e na compreensão das ações dos sujeitos urbanos. Na visão de Certeau (2008), ao invés de se analisar o fenômeno urbano a partir da perspectiva cidade-conceito, existe a possibilidade sempre evidente de se enveredar por outros caminhos, que procuram análises diversas sobre as práticas microbianas, singulares e plurais, existentes num sistema urbanístico. Essas práticas microbianas, muitas vezes, escapam aos ditames dos processos de racionalização das cidades, sem ao menos ficarem fora do campo onde se exercem, o que deve levar, salienta Certeau (2008), às teorizações sobre as práticas cotidianas, sobre o espaço vivido e sobre uma inquietante familiaridade da cidade.

Esse deslocamento realizado por Certeau (2008) é que permite observar, num contexto próprio de manifestações da atividade de camelô no conjunto daqueles negócios surgidos no entremeio à reestruturação produtiva, práticas cotidianas diversas e enriquecidas sobre o funcionamento e a dinâmica desse comércio, no sentido de uma reprodução/ modificação constante do espaço vivido. Se existe familiaridade sobre a atividade de camelô, isso se deve mais a produção e categorização de conceitos do que ao entendimento dos fatores simbólicos constituídos nesta modalidade de comércio.
É neste ponto que Certeau (2008) elucida as "enunciações pedestres" e as "retóricas ambulantes", no sentido de mostrar os possíveis processos e as apropriações simbólicas constituídas nas práticas urbanas. Tendo como base o ato de caminhar, Certeau (2008) analisa que, numa ordem espacial definida que organiza conjuntos de possibilidades (lugar por onde se pode trafegar) e proibições (um muro que impede prosseguir), há variações e improvisações que privilegiam, mudam ou deixam de lado elementos espaciais, dando e ressignificando os elementos simbólicos. Por esse motivo, a cidade pode ser observada em suas práticas micro, pulsantes e cambiantes, mas que não deixam de estar vinculadas à lógica da ordem ditada pela cidade-conceito.

É nesse ponto que fatores vinculados à organização das cidades e às relações simbólicas estabelecidas entre a população e os camelôs permitem análises diversas sobre a atividade de camelô e suas interfaces culturais. No quadro dessa discussão é que este ensaio se efetiva. Primeiramente, no deslocamento, seguindo os passos de Certeau (2008), da cidade-conceito para as práticas urbanas. 0 intuito é analisar as diferenças e singularidades existentes em estudos etnográficos realizados no mercado camelô em cidades e espaços diferenciados. Segundo, na desmistificação, distanciando-se das considerações de Harvey (2005), da lógica estabelecida na reestruturação produtiva, que forma duas categorias ou cidade dual: uma centralizada e outra marginalizada. A intenção é utilizar estudos etnográficos realizados na atividade de camelô para mostrar que, mais do que uma cidade dual, o que se tem muitas vezes é uma cidade híbrida.

Assim, o objetivo neste ensaio foi estudar a atividade de camelô a partir das discussões e dos conceitos de cidade e território. Essa análise leva em consideração estudos etnográficos desenvolvidos no mercado camelô, bem como os dois elementos citados anteriormente e que permitem o quadro de discussão: primeiro, o deslocamento da ideia de cidade-conceito para o de práticas urbanas; e segundo, a desmistificação da lógica estabelecida na reestruturação produtiva.

Para tanto, é necessária uma análise, no entremeio às discussões sobre os vários conceitos de cidade, assim como do funcionamento e das possibilidades da atividade de camelô. Tendo sido exposta essa discussão sobre os conceitos de cidade e 
as implicações da atividade de camelô neste entremeio, o segundo passo será um aprofundamento das discussões sobre a cidade na lógica das práticas urbanas, procurando salientar a importância de se observar essas práticas a partir dos microterritórios. Já o terceiro passo será a apresentação dos estudos etnográficos desenvolvidos no mercado camelô, contemplados nos trabalhos de: Machado (2004), Goularte (2008), Rodrigues (2008) e Quezada (2008). Por fim, no quarto passo, será realizada a análise dos fatores simbólicos evidenciados nos trabalhos etnográficos levando-se em consideração as discussões sobre cidade e território, permitindo o deslocamento para a ideia de práticas urbanas a partir dos microterritórios e a desmistificação da lógica na reestruturação produtiva.

\section{Considerações teóricas sobre a atividade de camelô no contexto da cidade}

A atividade de camelô da forma como é conhecida nos dias atuais tem sua transformação mais evidente a partir da década de 1970 (como no caso dos Estados Unidos), com o processo de reestruturação produtiva. Essa reestruturação ocasionou - como ficou visível na introdução deste ensaio - uma reorganização das relações de trabalho, impulsionando uma série de contingentes de pessoas desempregadas para as práticas econômicas da camelotagem. 0 camelô se constitui uma derivação da atividade de venda ambulante, mas com uma diferença um tanto significativa, pois o mercado camelô tem como peculiaridade fixar sua atividade em um determinado local, enquanto a venda ambulante, não (RODRIGUES, 2008).

Esse fato mostra que há uma relação evidente entre a atividade de camelô e as mudanças ocorridas no contexto das cidades, assim como em relação às manifestações mais evidentes em determinadas épocas da sociedade. Por esse motivo, o próprio conceito de cidade vai se alterar, realizando uma verdadeira (re)significação das atividades sociais e econômicas constituídas.

Nesta linha, com a intenção de evidenciar a concepção que autores tradicionais possuem sobre a ideia de cidade, é necessário verificar o pensamento de Marx e Weber. A cidade, na visão desses pensadores, tinha como fator peculiar a atividade industrial, de onde emergiu as relações de conflito entre classes (proletariados e detentores do capital). Nesta linha, a cidade assume o espaço onde o processo de exploração do trabalho é desenvolvido, de onde é possível constatar a miséria e a degradação das classes trabalhadoras. Tendo em vista a centralidade do sistema industrial à época em que Marx e Engels produziram suas constatações sobre a cidade, tais mercados informais surgiam nos guetos, sendo amplamente marginalizados e desqualificados em virtude do sistema industrial constituído (SANT'ANNA, 2003).

É desta vertente que Lopes (2004) analisa o surgimento do mercado informal na casta da sociedade constituída pelos escravos ou libertos, crioulos ou africanos e também brancos pobres. A autora salienta ainda que, tendo em vista uma elite local, houve o impulso para o controle e a imposição de disciplinas para essa categoria. A partir de tal confronto, surge o dilema da "livre circulação de mercadorias" dentre os pressupostos das atividades praticadas por essa elite, o que levou às perseguições a esse mercado informal. Além disso, esse mercado sempre esteve marginalizado e rechaçado, como salienta Lopes (2004), pelas implicações legais não atendidas, mas ainda mais pelo grupo social que conduzia essas atividades.

Diferentemente de Marx e Engels, Weber (1973) procura dar outras significações para a ideia de cidade. Primeiro Weber (1973) diz que a cidade, num sentido econômico, seria o espaço onde os habitantes vivem do produto da indústria ou do comércio, e não da agricultura. Segundo que, diferente das formações existentes na Grécia antiga, há nas cidades uma forma de governo peculiar, constituída por meio de uma burocracia própria. Mas o que impulsiona essa formação social, considerava Weber (1973), é a existência de um mercado e de consumidores. Por esse motivo, o autor analisa no espectro das cidades as diferenças entre consumidores, a partir da renda, do acesso aos produtos, da estrutura monopolista da troca, onde o comércio se concentra nas mãos de uma aristocracia urbana. Nesta linha, novamente, o mercado informal possui sua existência ligada a esse segmento em que a renda e o acesso aos produtos gerados pelo sistema industrial são limitados.

Tendo em vista essa burocracia própria à cidade, Lopes (2004) salienta que os mecanismos 
utilizados até hoje intentam direcionar quem circula pelas ruas e logradouros públicos da cidade, instituindo jaulas invisíveis e sutis da circularidade dos espaços. Essa organização das cidades cria não somente a ilegalidade gerada no comércio informal em comparação ao comércio desenvolvido por uma elite local, mas também a apropriação dos espaços urbanos, como ficará claro mais adiante.

Em contraposição a essas concepções tradicionais sobre a cidade, aparecem novas perspectivas impulsionadas pelas mudanças geradas no contexto da sociedade ocidental desde o processo de revolução industrial, sendo elas: a Escola de Chicago e a sociologia francesa. A Escola de Chicago introduz a ideia de uma ecologia urbana, no sentido de um determinismo urbano sobre os processos sociais desenvolvidos naquela delimitação geográfica. Essa análise permite maior complexidade na visão do fenômeno urbano, elucidando os vários problemas gerados dentro desse sistema, como o crescimento demográfico, o surgimento de guetos com pessoas de nacionalidades diversas, as condições de infraestrutura precárias etc. Nesta temática, apesar do limitado aporte em verificar e constatar a lógica das transformações no interior das cidades, por considerar esses eventos problemáticos, as ideias de sistema, de transformação e de movimentação, que acontecem sob uma cultura da cidade, possibilitam constatações diversas sobre a produção e reprodução das cidades, bem como sobre as formas de governo e de gerenciamento. Em relação a este último tópico, tendo em vista a ideia de cidade problema, o processo de governo das cidades recai basicamente sobre a resolução desses problemas - influência decisiva sobre vários governos de cidades - de onde o mercado camelô passa a ser um dos alvos (SANT'ANNA, 2003).

É necessário elucidar mais alguns fatores ligados à atividade de camelô. Pela própria informalidade $\mathrm{e}$ ilegalidade nas ações, esse mercado, em muitos casos, ocorre pela apropriação de locais públicos para o comércio, geralmente em praças e calçadas de maior movimentação. Considerando-se aquilo que Weber (1973) chamou de uma racionalização do sistema urbano, no sentido de uma série de normas e leis aplicadas às áreas urbanas que coordenem os fluxos econômicos e populacionais, as apropriações dessas áreas se constituem como ações ilegais, uma vez que os locais são de movimentação pública e de competência do poder público. Além desta ilegalidade na apropriação, o que a Escola de Chicago impulsiona no sentido de governo das cidades é a lógica de organização do espaço público, de onde ações de eliminar ou transferir esse mercado para locais devidamente organizados são fundamentais para o bom funcionamento do sistema. Essa lógica de organização e eliminação dos problemas urbanos gerou a constituição de locais específicos para a prática da camelotagem, com a construção do que ficou conhecido como camelódromos ou até shoppings populares. Apesar da legalização (formalização) em relação ao local apropriado, ainda há a ilegalidade em várias ações, como na compra de produtos contrabandeados.

As críticas à Escola de Chicago vieram da sociologia francesa, como forma de mostrar que não há uma cidade per se. Assim, as cidades são produzidas nas relações sociais e são organizadas de acordo com essas relações e com o controle político. Toma destaque nesta temática de cidade as relações de consumo, produção, poder e troca. Um dos autores vinculados a essa sociologia francesa é Castells (2000). Esse autor chama a cidade na atualidade de cidade informacional, com a intenção de mostrar que as tecnologias de informação e de comunicação possibilitam reestruturações na produção do espaço urbano, instituindo espaços de fluxos, de onde as relações de poder e riqueza tomam centralidades cambiantes no próprio tamanho das cidades. Com isso, Castells (2000) mostra que há uma centralização dos mercados financeiros nas regiões metropolitanas, assim como a descentralização dos escritórios de processamento de dados para as regiões menores.

Na lógica instituída por Castells (2000), a cidade informacional se constitui como a forma espacial e social da sociedade de nossa época, assim como a cidade industrial se constitui a forma urbana da sociedade hoje em crise. Neste contexto, há uma mudança evidente na lógica econômica e social, que produz uma nova forma de cidade. Se, no caso da cidade industrial, as formações sociais se concentravam no entorno dos processos de fabricação e o mercado informal era fonte de trocas e comércios nas margens e nos guetos, no caso da cidade informacional os processos sociais vão se concentrar no sistema financeiro, e o mercado informal adentra as regiões centrais nas cidades. Neste modelo 
de cidade informacional, o sistema industrial acaba sendo transferido para margem do espaço urbano (exemplo disso são os distritos industriais), enquanto o sistema financeiro e de circulação de moedas tomam centralidade (agências bancárias e financeiras). Tendo em vista essa lógica de circulação é que o mercado camelô, assim como o mercado ambulante, passa a funcionar não mais na periferia, mas próximo às regiões centrais, onde o sistema financeiro se constitui.

Castells (1973) mostra esse fato na forma de uma cidade dual, onde existe o desenvolvimento tecnológico crescente ao mesmo tempo em que gera pobrezas inimagináveis. Do mesmo modo que o crescimento dos grandes centros possibilitou formas cada vez melhores de estrutura tecnológica e de emprego, gerou também a existência de uma massa cada vez maior de desempregados. Se há o desenvolvimento de tecnologias que possibilitaram reestruturações produtivas importantes, houve também o desenvolvimento cada vez maior da economia informal. Neste paralelo já não há mais a divisão assimétrica entre os espaços de industrialização centralizados e os espaços de mercados informais marginalizados, pois o que vai ocorrer é a dualidade de convivência num mesmo espaço entre essas estruturas produtivas e o sistema financeiro com as atividades informais.

A partir da cidade informacional de Castells (2000) surgem outras perspectivas sobre o projeto urbano que transcende as formas tradicionais de observar as cidades. Um fator importante, que é possível de ser destacado das discussões de Castells (1973) e que, de uma forma ou de outra, perpassa outras concepções sobre a cidade, é a ideia proveniente dos novos sistemas de informação e dos espaços virtuais produzidos. É neste sentido que surge a cidade global, discutida por Sassen (1998), onde ocorre a integração de sistemas assim como a dispersão geográfica. Na cidade global há manifestações de mercados globais e locais, assim como pontos de comando e atividades bancárias, que tornam esses espaços produzidos na forma de cidade, locais de manifestações de atividades gerais que estão conectadas em rede.

Mas a cidade contemporânea não é apenas uma manifestação do global no local ou vice-versa, mas também pelas relações virtuais proporcionadas pelas novas tecnologias de informação. Essas relações virtuais produzem aquilo que Lévy (1999) chama de cibercidade, na qual a ideia de cibercultura realiza uma articulação entre as manifestações territoriais e a possibilidade cada vez mais elaborada de comunicações interativas e coletivas que geram e difundem ideias, recursos e conhecimentos. Ainda nesta linha, Mitchell (2003) realiza uma discussão interessante sobre aquilo que ele chamou de e-topias, ao dizer que a cidade contemporânea funciona como espaço inteligente, onde as novas tecnologias possibilitam maior circulação de moeda (em bits) e economia de recursos (por exemplo, ler uma reportagem ou e-mail na tela do computador evita a impressão no papel), o que torna as cidades econômicas e ecológicas ao mesmo tempo. Mas o interessante na análise de Mitchell (2003) é a discussão sobre as transformações suaves, o que possibilita verificar a cidade como território de mudanças e adaptações constantes, além de (re)configurações de espaços públicos e privados.

Neste sentido, o olhar que Lévy (1999) e Mitchell (2003) possuem é proveniente dos grandes centros e das zonas mais desenvolvidas, de onde essas manifestações são sempre evidentes. Isso não quer dizer que os pequenos centros e as zonas menos desenvolvidas não sofram influências constantes dessas ciberculturas ou dessas e-topias, mas de que em determinados locais manifestações das cidades tradicionais ainda são evidentes e convivem com a (re)produção dessas novas temáticas urbanas. Esse fato possibilita um hibridismo e a existência múltipla de várias coisas num mesmo espaço que liga o material e o imaterial, por meio de uma rede complexa de relações.

Ainda nesta linha de pensamento, Mitchell (2003) redesenha o conceito de cidade dos bits e, juntamente com essa ideia, focaliza as manifestações mais evidentes de conexão entre a noção de espaço e subjetividade. Enquanto no contexto dos bits há a evidente revelação de identidade em pseudônimos eletrônicos, no contexto dos espaços sociais existe a possibilidade sempre crescente de manifestação de identidade pelos espaços frequentados, assim como a própria frequência em determinados espaços limita o acesso a outros. Já não é mais sobre concepções psicológicas e biológicas apenas que existe a manifestação das identidades, mas no caso do espaço urbano a própria dispersão e a maneira de ocupação possibilitam o surgimento 
de identidades fragmentadas, fluidas e adaptadas, como salienta Mitchell (2003).

Diante dessas discussões e do contexto para onde estão destinadas, pode ocorrer a impressão de que a atividade de camelô, assim como o mercado informal, está muito aquém dessa discussão, que mais parece ser sobre uma cidade do futuro. Inserir os avanços tecnológicos nas considerações sobre as cidades é colocar todo empreendimento de constatação numa cidade do futuro, onde esse tipo de mercado [camelô] faria parte de um passado não muito promissor. Mas se mesmo nos grandes centros urbanos e nas cidades onde essa realidade do ciberespaço ou das e-topias ainda é possível constatar a manifestação desse mercado camelô, é porque seu surgimento pode ter sido estimulado por todos esses avanços ou por todas essas formas de comunicação e informação que criaram maneiras peculiares de consumo, produzindo contornos cada vez mais elaborados de obtenção de produtos com a economia de recursos.

0 mercado camelô no contexto das cidades serve amplamente à possibilidade sempre presente de manutenção dos ciberespaços, das e-topias, da desmobilização e da personalização em massa. Apesar da ideia de ponto fixo, em relação ao espaço ocupado, o mercado camelô é dinâmico e fluido, tanto na disseminação e distribuição dos novos conceitos e produtos, como na possibilidade sempre presente de colocar tais produtos e conceitos ao alcance de consumidores. Apesar de o mercado camelô ser visto como um mercado informal, dominado, em grande parte, por um contingente de pessoas na condição de trabalho informal, esse mercado, numa análise sobre as ideias de cibercidades ou e-topias, serve à fluidez, circulação, sustentação e produção - em grande parte - desse espaço virtual que domina o contexto da cidade. Isso feito por meio dos vários produtos eletrônicos comercializados, o que permite a integração de vários contingentes populacionais a esse mundo virtual.

Ainda nesta linha é necessário fazer uma análise sobre o conceito de mercado informal, que serve a um amplo espectro de manifestações. 0 mercado informal pode estar ligado, como já salientado, à precariedade e à pobreza, também ao não cumprimento das leis econômicas de mercado e da legislação trabalhista, assim como a ilegalidade nos processos de ocupação e pagamento dos tributos às esferas públicas. No caso do mercado camelô, ressalta Goularte (2008), a ilegalidade está vinculada, muitas vezes, ao não cumprimento da legislação trabalhista e também, em situação bastante presente, à revenda de mercadoria sem nota fiscal e ao contrabando e pirataria de produtos. Esse fato causa a circulação cada vez maior de mercadorias com baixos preços, bem como a fluidez e limitada permanência destas categorias de mercado nos locais apropriados. Por esse motivo, numa conotação sobre cidades, a ideia de fluidez do espaço urbano é sempre retomada, no sentido de uma mudança constante nos processos sociais.

Essa fluidez do espaço urbano é temática recorrente no trabalho de Solà-Morales (2002). Nesta temática, o espaço urbano assume formas fluidas, cambiantes, capaz de fazer fisicamente o corpo no mutável, assim como dar forma física ao tempo, no sentido de verificar uma durabilidade na mudança. Na visão de Solà-Morales (2002) o espaço urbano deve ser visto a partir de temáticas territoriais, não somente como sistema de espaço habitado, mas como ponto de partida, lugar de encontro da atividade formativa. Apesar da ideia de território exprimir a dominação e a permanência, Solà-Morales (2002) verifica que essas concepções fixas fazem parte de uma lógica euclidiana plana e tridimensional, ligada à permanência, mas que nos modelos e formas constituídos nas cidades, o que se torna visível é uma durabilidade na mudança mais do que o predomínio do espaço imutável no tempo. Se o que diferencia o mercado camelô da atividade ambulante é o desenvolvimento desse mercado em locais fixos, isso não quer dizer que não há mutações nesse processo de apropriação, mas que existe certa durabilidade na mudança. Tendo em vista essa apreensão de Solà-Morales (2002) sobre a concepção do espaço urbano como território é que se torna evidente uma articulação melhor entre as discussões sobre cidade e território.

\section{Articulando as discussões sobre cidade e território}

Para compreender o deslocamento da cidade-coisa para a cidade-território, é necessário aprofundar algumas considerações de Certeau (2008). Esse autor analisa o fenômeno urbano a partir de 
duas perspectivas: a cidade-conceito, que se assemelha ao que foi concebido como cidade-coisa, e as práticas urbanas, vinculadas à ideia de cidade-território. Certeau (2008) observa essa mudança a partir de uma discussão sobre o olhar de um observador do topo de um prédio, de onde é possível detectar o espaço geométrico das construções visuais, de onde opera a existência de um espaço próprio e delimitado, com sua organização e subdivisão em relação aos elementos constituintes desse sujeito universal que é a cidade. Nesta temática, salienta Certeau (2008), a cidade oferece a capacidade de conceber e construir o espaço a partir do número finito de propriedades estáveis, isoláveis e articuladas uma sobre a outra.

Ora, essa maneira de observar a ideia de cidade não é recente, nem muito menos deixou de ter sua importância nos estudos urbanos, principalmente quando a lógica instituída é da eliminação ou exclusão daquilo que se torna detrito de uma administração funcionalista. Os processos de organizar, dividir e controlar concedem as bases para uma cidade soberana em si mesma, que privilegia o progresso (o tempo) e - na análise de Certeau (2008) - faz esquecer a sua condição de possibilidade que é o próprio espaço. Por esse motivo, Certeau (2008) desloca as discussões sobre a cidade-conceito para as de práticas urbanas, remetendo às formas específicas de "operações" (maneira de fazer), juntamente com outra forma de espacialidade (uma experiência antropológica, poética e mítica do espaço) e uma mobilidade opaca e cega da cidade habitada.

Nesta linha de pensamento é que as possibilidades de uma cidade em fluxos se tornam evidente. Não é o olhar das formas geométricas e geográficas - vista pelo alto - que dá forma à cidade. A forma é constituída na fluidez, circulação, sustentação e produção do espaço que domina o contexto das cidades. Isso é observado nas práticas urbanas, peculiares, móveis e cambiantes que instauram o cotidiano inventado e reinventado. Somente a partir dessa mobilidade, das interconexões e das redes de contato é que há a produção das cibercidades, das e-topias e das cidades informacionais. Por esse motivo, Solà-Morales (2002) analisa as práticas urbanas por meio de perspectivas territoriais, como forma de verificar as formas de mutação, fluidez e durabilidade da mudança nas práticas urbanas.
Numa intersecção entre a sociologia e a geografia no espaço urbano, George (1969) salienta que os grandes temas de estudo sobre os grupos humanos se concentram em duas vertentes: (1) o tema do trabalho, que é o tema das atividades e da produção; e (2) o tema da existência, subdividido em três ramos: habitação, consumo e movimentos. Sem ter a intenção de adentrar especificamente sobre a discussão do trabalho que, apesar de evidente na atividade de camelô, possui uma amplitude de temáticas que fogem ao escopo das análises desenvolvidas até este ponto, cabe especificar algumas considerações de George (1969). Primeiramente, a constatação de diferenças entre o trabalho rural e o trabalho urbano, que denota formas específicas de realização das atividades e da produção. Assim, o trabalho industrial, na análise desse autor, ofereceu o impulso vigoroso ao desenvolvimento das cidades, e os termos industrialização e urbanização, em um passado não muito distante, foram complementares. Essa relação entre industrialização e cidades ficou clara no início da discussão sobre o conceito de cidade, particularmente nos trabalhos de Marx e Weber. Vale salientar que nos dias atuais essa relação entre industrialização e urbanização são termos desconexos, pois em muitos países da África, da Ásia e da América Latina, a urbanização ocorreu desvinculada da industrialização.

Tendo essas relações estabelecidas no contexto das cidades, considera George (1969), o seu estudo é inseparável dos sistemas de relações, que são, ao mesmo tempo, sistemas econômicos e técnicos, demográficos, culturais e afetivos. Essa amplitude conferida por George (1969) nos estudos sobre a cidade já se torna um deslocamento importante para o entendimento das atividades e da produção desenvolvida no contexto das cidades. Num outro ponto se instaura o que George (1969) chama de existência, que concentra tudo aquilo que não está diretamente manifestado no trabalho e na produção, que é a habitação, o consumo e o movimento. Na análise desse autor, no contexto das cidades, habitar confunde-se com residir, enquanto local dissociado do lugar onde se exerce a atividade profissional.

Após essa análise, George (1969) diz que o segundo tema é o consumo, enquanto forma dada e adquirida nas cidades de manutenção da existência. No contexto das cidades, existe um grande número de mercadorias - proveniente do desenvolvimento 
do sistema industrial - e de serviços prestados, o que muitas vezes tem feito sociólogos e filósofos chamar a sociedade atual de sociedade do consumo. Por fim, George (1969) fala da movimentação enquanto o processo de circulação de pessoas e mercadorias existentes numa cidade. Essa movimentação que confere a mudança constante da paisagem urbana, sem que isso seja perceptível em relação às estruturas construídas.

Essa articulação e esse deslocamento feito em relação ao pensamento de George (1969) possuem algumas importâncias centrais para o que se intenta constituir nas próximas discussões. Primeiro que, ao analisar o contexto da atividade de camelô, fica evidente a impossibilidade de se desvincular de temas importantes como o trabalho, a produção, o consumo, a movimentação e a habitação, que fazem parte de uma lógica específica das cidades contemporâneas. É em virtude dessa constatação que Certeau (2008) se insere na dinâmica das práticas cotidianas, dando ênfase ao processo de caminhar, o qual possibilita transcrever os traços (densos ou leves) e as trajetórias (passando por aqui e não por lá). Esse ato permite formas cada vez mais elaboradas de conceber os espaços urbanos, de se entremear nas atividades e na produção, de conhecer as manifestações de consumo, de observar a lógica das habitações e das construções, assim como entender as enunciações dos pedestres.

É desta forma que nem os estudos sobre as cidades nem os estudos sobre os territórios estão aquém de intercederem também aspectos culturais e econômicos. 0 que Certeau (2008) permite detectar em sua análise sobre as práticas cotidianas é a possibilidade de apreensão das formas culturais e econômicas encontradas na movimentação e nos fluxos nas cidades. Nesta mesma linha também está a crítica que Souza (2009) realizou sobre o conceito de território, ao dizer que esse não é apenas um conceito político, mas congrega também os fatores culturais e econômicos. Não há como negar, como esse autor prefere expor, que o poder é uma das principais dimensões na discussão sobre territórios, mas que seria ingênuo pensar que essas manifestações de poder não estivessem vinculadas aos fatores culturais e econômicos. Além desse fato, salienta Souza (2009), instituir a separação entre o "político", o "cultural" e o "econômico", da maneira como é feita, tem muito de cartesiana, de artificialmente preocupada em separar aquilo que é distinguível, mas não é propriamente separável.

Dessas conotações se podem extrair duas vertentes. A primeira é a possibilidade de estudar os fenômenos urbanos a partir das práticas instituídas no contexto das cidades. E isso pode ser feito, de acordo com as considerações de Certeau (2008), a partir das microunidades, que no caso aqui instituído é um estudo sobre o mercado camelô. Segundo, que essa intersecção das discussões sobre territórios no ambiente das cidades também permite uma análise sobre os "nanoterritórios", como prefere chamar Souza (2006), de onde as manifestações de poder estão enredadas nas práticas de ocupações dos espaços, além de serem compreendidas não somente por análises políticas, mas econômicas e culturais.

\section{Aprofundando o entendimento: estudos sobre a atividade de camelô}

Para realizar a articulação é necessário elucidar, no entremeio à atividade de camelô, os pressupostos existentes nas discussões sobre território e cidade. Para isso, partir-se-á das articulações geradas por outros autores (GOULARTE, 2008; QUEZADA, 2008; RODRIGUES, 2008; MACHADO, 2004) sobre a própria atividade de camelô, desenvolvida em trabalhos etnográficos e de pesquisas nas áreas de ciências sociais e humanas, como forma de uma compreensão sobre tal atividade.

Assim, Goularte (2008), ao estudar a atividade de camelô, foca suas análises sobre a identidade e a história dos sujeitos camelôs da cidade de Pelotas, RS. Primeiro essa autora faz um resgate do conceito de camelô, concluindo que são aqueles vendedores ambulantes ou fixos que carregavam suas mercadorias nas costas, tais quais os camelos no deserto. Essa forma de transporte ainda se verifica, salientou Goularte (2008), entre aqueles que realizam o contrabando de mercadorias do Paraguai, pois muitos, taxados como sacoleiros, realizam esse tipo de transporte. Este se torna um forte atributo ligado à identidade desses sujeitos que, diferente daqueles considerados comerciantes, possibilitam a venda dos produtos a um preço atrativo em razão da compra destituída de muitos impostos e do não pagamento de muitos impostos no processo de revenda. 
Apesar de a denominação "camelô" impactar amplamente essa atividade de comércio de forma pejorativa e degradante, ressalta Goularte (2008), o que se verificou foi uma série de estratégias utilizadas por vários desses sujeitos a fim de se tornarem mais comerciantes do que camelôs. Essas estratégias, salienta a autora, estão pautadas nas tentativas de regularização da atividade por meio, por exemplo, da assinatura das carteiras dos funcionários, da formalização da atividade como microempresa e do pagamento de impostos. Goularte (2008) verificou que os camelôs não poderiam, mesmo que o quisessem, assumir uma identidade centrada no ser camelô em tempo integral - pois muitos não são mais camelôs - se por meio dessa palavra o que se quer é associar significados tão comuns como os de: precariedade no trabalho, desemprego formal, falta de opções, baixos rendimentos e ilegalidade em relação aos registros da atividade. Isso pelo fato de que a pesquisa conduzida por Goularte (2008) foi desenvolvida num camelódromo, o que possibilitou constatar essa ampla ambiguidade entre ser um verdadeiro comerciante ou apenas camelô.

Goularte (2008) menciona que os camelôs não são comerciantes, visto o lugar que ocupam ser nomeado de "camelódromo", assim como o fato de as mercadorias comercializadas serem fruto, em sua maioria, de contrabando e pirataria. Também não são poucos os relatos sobre as viagens em busca de mercadorias, sempre repletos de traumas, medos, inseguranças e também sucessos. Essas constatações mostram que há, na constituição dos camelódromos, aspectos de uma historicidade que ainda liga os camelôs à temática da precariedade e da informalidade, bem como àqueles aspectos vinculados a legalidade e certa formalidade. No que tange à aquisição das mercadorias, ainda os camelôs exercem a atividade de forma tradicional, mas no processo de comercialização existe a evidência de vários aspectos ligados à formalidade e legalidade nas ações com a constituição dos camelódromos, em razão da proibição de venda de determinados produtos (por exemplo, cigarros, CDs e DVDs), assim como a necessidade de formalização do negócio como microempreendedor individual.

Mas essa é uma história recente nos processos urbanos iniciados nos centros de maior porte, como fez Goularte (2008), ao desenvolver sua etnografia junto aos camelôs da cidade de Pelotas/RS. Mesmo assim, em outros centros, como o Rio de Janeiro, ainda a atividade na forma tradicional, de dominação e apropriação dos espaços públicos, é exercida. Isso fica evidente no trabalho de Quezada (2008), que desenvolveu uma etnografia entre os camelôs do bairro de Copacabana, no Rio de Janeiro. Essa autora inicia sua discussão apresentando a história do mercado ambulante no Rio, e afirmando que, no início do século XX, tal mercado era visto como atrasado e insalubre em relação às atividades desenvolvidas e modernas. Assim, o mercado ambulante tinha certa importância, apesar da ilegalidade, da informalidade e da paisagem "poluída" pela quantidade de ambulantes. Sua importância estava centrada na circulação de alimentos, de produtos artesanais e manufaturados e, também, de pequenos serviços.

Apesar de ser considerado um "problema social", salienta Quezada (2008), o mercado ambulante no Rio era visto, nesta época, de forma secundária, pois a preocupação do poder público era com a limpeza e modernização da cidade do Rio de Janeiro. Ainda que tal atividade acabasse por gerar uma interferência negativa na paisagem urbana, esse mercado se tornava marginalizado nas preocupações sobre a cidade em si. Essa visão romântica, segundo Quezada (2008), se alterou radicalmente a partir da década de 1970, com a necessidade de instituir atividades modernas, regulamentadas e legalizadas. 0 mercado ambulante, apesar de ser considerado uma instituição urbana, tornou-se um problema público e social, dado o vínculo que este mercado tinha com a pobreza, a marginalidade e a precariedade nas relações de trabalho. Em virtude dessa conjuntura, a partir de 1973, num levantamento feito por Quezada (2008) nos noticiários da época, surge o que ficou conhecido como "guerra contra os camelôs". A figura do camelô aparece, no Rio, vinculada ao contrabando e à pirataria de mercadorias. Esses camelôs, para se furtarem da fiscalização, utilizavam bolsas de viagens ou sacolas de casas comerciais, numa tentativa de livre trânsito. Isso fica evidente na seguinte passagem da escrita etnográfica de Quezada (2008, p. 9):

A onipresença dos camelôs estava nos seus pregões que enchiam o ambiente, nas calçadas das quais se apossavam para expor suas bugigangas, e no seu imenso contingente que transformava o Passeio numa "praça de mercado". No improviso 
de papelões, ripas de madeiras, lonas plásticas, ou próprio corpo, uma gama de vendedores ofertava as mais variadas mercadorias: chocolates, balas, canetas, chaveiros, antiguidades, miudezas... De repente, que susto! Um grito de "Olha o rapa!" (Guarda municipal) seguido de uma movimentação incompreensível tomou conta do lugar. Em questão de segundos todos os camelôs haviam desaparecido. Num piscar de olhos, codificaram a mensagem, recolheram suas mercadorias, fechando suas bancas de madeira e escolhendo a melhor rota de fuga. Após o alerta salvador, a rua se transformara num outro ambiente, numa outra paisagem, mais fluida e arejada, porém menos estimulante. Com a rua agora completamente livre dos ambulantes, pude então me dar conta do barulho infernal que faziam.

Esse trecho apresenta, além da guerra contra os camelôs, a transformação do mercado ambulante em mercado camelô, que se constitui a partir da fixação dessas estruturas improvisadas em pontos específicos da cidade, assim como em pontos específicos do próprio lugar de prática da atividade. Na descrição de sua trajetória etnográfica, Quezada (2008) mostra que, ao se familiarizar com o campo em estudo, pôde perceber que os camelôs montavam suas bancas de madeira, seus paraquedas e aramados sempre nos mesmos lugares, sempre nos mesmos pontos fixos. Isso permitiu que a pesquisadora vislumbrasse as mercadorias vendidas em cada barraca de camelô e como ocorriam as negociações.

Quezada (2008) salienta que existiam camelôs mais assíduos e dependentes da camelotagem, enquanto outros funcionavam mais como "camelôs ambulantes", que procuravam desenvolver a função como forma de aumentar a renda familiar. Essa autora constatou que tal prática era muito evidente, no ambiente do mercado camelô de Copacabana, em épocas comemorativas (Dias das Mães, Natal e Dias das Crianças). Geralmente, passada a euforia do momento, esses camelôs desapareciam, dando lugar à rotina dos camelôs fixos, e, vez ou outra, alguns desses camelôs ambulantes se fixavam no lugar e a atividade de camelotagem se tornava central.

Além dessas duas denominações - "camelôs" e "camelôs ambulantes" -, Quezada (2008) constatou que entre os camelôs era possível distinguir duas categorias: aqueles que se especializavam em mercadorias de determinados gêneros e aqueles que se aventuravam na venda de qualquer coisa que contivesse a potencialidade de retorno financeiro. A primeira categoria era mais conservadora e avessa ao risco, enquanto a segunda categoria era mais ousada diante da efemeridade da moda. Esse fato os conduzia também a lugares frequentados por públicos específicos, dados a especialidade e a diversidade dos produtos (eletrônicos, enfeites, bugigangas, CDs e DVDs etc.).

Tendo em vista outro trabalho etnográfico realizado entre os camelôs das cidades de Marília, SP, e Presidente Prudente, SP, essa discussão sobre a diferença entre camelôs e ambulantes ainda é evidenciada. Rodrigues (2008) salienta que os camelôs possuem ponto fixo nos camelódromos ou nas ruas, enquanto os ambulantes, não. Como a temática de estudo de Rodrigues (2008) é sobre a ideia de território, na visão do autor, a atividade de camelô possui como peculiaridade o espaço conquistado e dominado para o exercício de sua função. Além dessa peculiaridade, Rodrigues (2008) identifica que, nas atividades de camelôs das cidades de Presidente Prudente, SP, e Marília, SP, existem também diferenças entre o camelô e o sacoleiro. Enquanto o camelô possui um ponto fixo e se concentra, em grande parte, nas atividades de comercialização dos produtos nesses pontos, o sacoleiro prefere não possuir esse ponto fixo e se especializa na aquisição dos produtos nos grandes centros e, principalmente, no Paraguai. Assim, os sacoleiros se concentram em estratégias de compras e melhores locais com baixos preços e, muitas vezes, revendem parte dessas mercadorias para os camelôs.

Observando essas peculiaridades, Rodrigues (2008) detecta aquilo que ele prefere chamar de circuito da camelotagem; ou seja, a relação articulada do trabalho efetuado pelos camelôs com as atividades conexas, sendo estas realizadas por outros trabalhadores, mas que em alguns casos podem exercer mais de uma atividade. Em outras palavras, afirma Rodrigues (2008), um trabalhador camelô pode ser ao mesmo tempo camelô e sacoleiro, ou camelô e ambulante, ou camelô e "laranja" (pessoal utilizado para dividir a cota máxima nas compras realizadas pelos camelôs), ou até mesmo possuir um boxe e trabalhar no setor formal sob relação de assalariamento, ou ser proprietário de comércio legalizado. Neste caso, é possível garantir 
o abastecimento dos estoques de mercadorias, via comercialização e apresentação parcial de notas fiscais, mesclando mercadorias de procedência duvidosa com as mercadorias declaradas, bem como adicionar uma marca registrada a uma imitação ou falsificação de mercadoria.

Mesmo verificando esse circuito da camelotagem, Rodrigues (2008) observa que aquilo que define o trabalhador camelô enquanto tal é exatamente a posse do ponto fixo cuja disputa, conquista e controle é fator fundamental dos inúmeros conflitos que permeiam esta atividade. No jogo de forças estabelecido, comparecem como seus principais protagonistas os trabalhadores camelôs, as Associações Comerciais, o Poder Público Municipal, os lojistas e o Sindicato do Comércio Varejista. Com essa discussão, Rodrigues (2008) traça o panorama geral de uma análise territorial da atividade de camelô, mas deixa discussões relacionadas aos aspectos culturais à margem de sua pesquisa.

Para além dessa discussão e retomando o que Rodrigues (2008) chamou de circuito da camelotagem, as relações estabelecidas nas diversas atividades conexas são importantes para se compreender a dinâmica na existência da atividade de camelô. Esse autor constrói, de forma esquemática, o trajeto realizado na compra das mercadorias vendidas pelos camelôs, assim como elucida as várias atividades conexas existentes na dinâmica de circulação dessas mercadorias. Na primeira articulação existe a relação entre camelôs e sacoleiros. Enquanto alguns camelôs podem e exercem a função de sacoleiro, em outros casos há a nítida diferença entre aqueles que comercializam os produtos em pontos fixos (camelôs) e aqueles que se entregam ao contrabando ou à circulação de mercadorias (sacoleiros). É desta primeira articulação (camelô-sacoleiro ou sacoleiro) que surge a segunda articulação, que é desenvolvida através dos meios de transporte desses camelôs para os grandes centros e, no caso do trabalho de Rodrigues (2008), para o Paraguai. Nesta parte aparecem os ônibus e também o condutor que, em muitos casos, assume o papel de sacoleiro.

A chegada em Foz do Iguaçu, PR, gera uma a terceira articulação, quando da parada de centenas de ônibus que são aguardados por vans a partir das três horas da madrugada. Rodrigues (2008) salienta que, neste momento, estabelece-se uma logística de transportes, coordenada via rádio ou celulares, realizada por trabalhadores brasileiros e paraguaios. Essas vans transportam os camelôs e sacoleiros até a ponte da Amizade - que liga a cidade de Foz do Iguaçu, no Brasil, à Ciudad del Este, no Paraguai. Na ponte da Amizade passa a funcionar a quarta articulação, nas figuras dos motoqueiros, dos passeros e dos barqueiros. Essa logística de transportes funciona nos dois sentidos e é utilizada tanto pelos camelôs e sacoleiros, quanto pelo comércio formal entre as duas cidades. Rodrigues (2008) explica a diferença entre passero e motoqueiro: o primeiro é de origem paraguaia e realiza o transporte tanto via motocicleta quanto a pé.

Já na Ciudad del Este surge a quinta articulação, que se constitui por meio da atividade dos carrinheiros. Esses carrinheiros, geralmente homens com idades variadas, transportam mercadorias de peso mais elevado em carrinhos de almoxarifado. Eles podem ser acionados pelos camelôs e sacoleiros, bem como pelos cajeros e mesiteros. Esses dois últimos grupos correspondem ao que conhecemos no Brasil como camelôs, que possuem ponto fixo nas ruas da Ciudad del Este, com pequenas barracas cobertas com lonas coloridas, as quais podem ser formadas por uma banca (mesita) ou um pequeno trailer ou, ainda, uma casinha de metal (caja ou casilha).

$\mathrm{Na}$ análise de Rodrigues (2008), a sexta articulação é perceptível quando observada a partir do Paraguai, onde os "laranjas" (pessoas utilizadas para dividirem as cotas de importação) são utilizados quando os camelôs e sacoleiros desejam levar o maior número de mercadorias. Para isso, eles fazem uso do "laranja", alugando o direito de adentrar a fronteira de outro país com cota legal de mercadorias, quando na verdade a mercadoria pertence a terceiros. Esses podem trabalhar, salienta o autor, para camelôs, sacoleiros, consumidores comuns, consumidores de grandes lojas do comércio formal e até mesmo para grandes redes de contrabando. Rodrigues (2008) detecta, ainda, que existem muitos "laranjas" no Paraguai que vivem em função dessa atividade, porém muitos sacoleiros e camelôs levam funcionários, parentes, amigos ou mesmo pessoas contratadas para assumirem especificamente essa função.

Com essa discussão, Rodrigues (2008) afirma que, em suma, camelôs, sacoleiros, "laranjas", carrinheiros, cajeros, mesiteros, paseros, condutores 
de vans, peruas e ônibus, e, por fim, os barqueiros constroem isso que o autor denominou de "circuito da camelotagem", uma vez que esses agentes tecem uma "teia" de atividades num circunscrito espacial de circulação de mercadorias que articula a atividade de camelô com as atividades conexas e de suporte.

Percurso semelhante ao de Rodrigues (2008) fez, anteriormente, Machado (2004), num estudo etnográfico sobre a circulação de mercadorias do Paraguai até os camelôs do centro de Porto Alegre, RS. Mesmo sendo um trabalho desenvolvido antes do de Rodrigues (2008), Machado (2004) possibilita um olhar mais complexo sobre as relações estabelecidas no contrabando ou compra de mercadorias no Paraguai. Essa autora, após anos de estudos etnográficos no mercado camelô de Porto Alegre, resolveu lançar-se a uma pesquisa etnográfica mais ampliada, indo até a origem das mercadorias adquiridas.

Machado (2004), em razão do longo período em campo, realiza o delineamento de vários temas de interesse da antropologia, como as relações simbólicas e de parentescos. Sem a intenção de explorar os vários meandros do trabalho de campo desta autora, algumas discussões são importantes, no que tange às relações de conflito estabelecidas com o poder público e também aspectos da legalidade e ilegalidade na atividade de camelô. Neste sentido, Machado (2004) explora em primeira mão a apropriação do espaço público, fazendo um resgate histórico do comércio de rua em Porto Alegre. Essa autora salienta que houve, desde o surgimento da cidade, uma forte presença, no Largo da Quitanda (atual Praça de Alfândega), do escambo e do comércio de peixes. A partir de 1815, com a construção do prédio dos alfandegários e a pressão dos grandes negociantes locais para a retirada daquele mercado de rua do local (em virtude do mau cheiro), esse mercado foi transferido para a Praça Paraíso (atual Praça XV de novembro), onde passou a ocorrer o mercado de rua de Porto Alegre.

Após essa transferência, a Praça Paraíso sofreu várias intervenções, como a construção e tentativa inicial de organização desse mercado de rua, em 1844, e uma nova reorganização dessa área com a construção de um novo mercado em 1869, de maiores proporções. A cidade foi se desenvolvendo e se instalou na região uma nova burguesia, entre 1890 e 1924, que vivia o sonho de uma cidade europeia, de onde as ações de moralidade passam a ter centralidade para o poder público. A partir de 1930, a cidade sofreu novas reorganizações, com o surgimento dos arranha-céus e da construção de longas avenidas. Nessa época, apresenta Machado (2004), o mercado ambulante tomou conta do centro da cidade e despertou na visão da sociedade daquela época um mercado atrasado, um submundo, um comércio pitoresco e abusivo, não condizente com a lógica de desenvolvimento de Porto Alegre.

Com esse resgate, Machado (2004) procura mostrar que a existência de um mercado ambulante não é recente em Porto Alegre, da mesma forma que os embates com o poder público - que sempre realizou ações para tentar organizá-los - e com os comerciantes locais - que pressionam para a eliminação desse tipo de mercado - sempre ocorreram nos arredores da cidade. No que tange à história recente, Machado (2004) realiza uma digressão sobre o crescimento do mercado chinês e sobre o surgimento de novas estruturas, como os shoppings centers, que se tornam novos espaços de sociabilidade, em detrimento dos mercados locais. Isso ocorreu no Brasil a partir da década de 1960, mas em Porto Alegre, o surgimento desses shoppings ocorreu em 1980.

Machado (2004) salienta que houve um deslocamento, consolidado na década de 1990, das elites da cidade de Porto Alegre para o consumo nos shoppings, tornando o centro da cidade um espaço de comércio e sociabilidade das classes menos favorecidas. Assim, com a intenção de renovação do centro, surgida nas políticas dos governos a partir de meados de 1990, o embate com os camelôs, que se espalharam pelo centro em busca dos mercados consumidores, foi central. Segundo a autora, a acusação dos governos dessa época era de q ue a atividade de camelô acabou por degradar o centro da cidade, assim como reduziu e, em muitos casos, eliminou o mercado consumidor das lojas existentes naqueles espaços. Por outro lado, Machado (2004) verifica que o surgimento do mercado camelô foi em função das mudanças e deslocamentos dos consumidores daquele bairro, dominado por consumidores de baixa renda.

Mesmo assim, os processos de contenção sobre a atuação de camelôs e ambulantes no centro de Porto Alegre foram iniciados - por meio da pressão realizada pelo Sindicato dos Lojistas (Sindlojas) 
sobre os órgãos reguladores - para coibir a atuação das atividades irregulares naquele espaço. Além disso, os fiscais realizam diligências aos locais de comércio ambulante e camelô com a intenção de eliminarem as atividades irregulares e fiscalizarem o comércio de produtos ilegais (proibindo a venda de cigarros, CDs e alguns aparelhos eletrônicos). Não foram raros - isso fica evidente no trabalho de campo de Machado (2004) - os confrontos verbais entre os fiscais da SMIC (Secretaria Municipal da Indústria e Comércio) e os camelôs. Aqueles vendedores ambulantes irregulares, quando de uma batida pelos fiscais das SMIC, recolhiam seus produtos e evadiam do local; algo semelhante ao que Quezada (2008) relatou em seu trabalho.

Porém, Machado (2004) expõe também que, apesar de essas duas categorias de poder serem nítidas, de um lado o poder público e os comerciantes regulares e, de outro, os camelôs e ambulantes, existe reciprocidade em muitas ações desenvolvidas por essas categorias, no que tange às relações de proximidade entre os fiscais da SMIC e os camelôs e ambulantes, assim como nas diversas relações de compra e venda desenvolvidas entre os camelôs e ambulantes e os lojistas.

Além dessas relações estabelecidas entre os camelôs e ambulantes com o poder público e os lojistas do centro de Porto Alegre, Machado (2004) transcende esse circunscrito e realiza algumas viagens junto aos camelôs e ambulantes para Ciudad del Este, no Paraguai. Para além da dinâmica instituída nas relações e nas atividades conexas visíveis no trabalho do Rodrigues (2008), Machado (2004) salienta os aspectos voltados para a legalidade e ilegalidade na comercialização dos produtos, mostrando o processo de metamorfose que sofre o produto de acordo com os contextos.

Machado (2004) cita um caso interessante que mostra essa metamorfose entre o legal e o ilegal, ao contar o caso do Seu Chico, que no Paraguai exige nota fiscal e, por enquanto, manifesta sua ação de legalidade, mas quando entra no Brasil com a mercadoria, procura esconder o que foi comprado dos agentes do Estado, onde sua condição muda radicalmente. Nesta linha, se o sujeito é um comerciante chinês e compra mercadoria contrabandeada da China, sua ação é ilegal, mas se ele compra diretamente da China, sua ação passa a ser legal. Ainda, se o sacoleiro compra sua mercadoria com nota fiscal e no valor máximo de 150 dólares, sua ação é legal; mas se ele extrapola esse valor e esconde o que extrapolou, sua ação passa a ser ilegal. Se ele é sacoleiro, mas sua mercadoria é pirata, sua ação pode ser legal por um lado, mas ilegal por outro. Se ele é camelô e vende uma mercadoria pirata, sua ação é ilegal; se ele é camelô irregular (caixinha), sua ação é mais ilegal ainda. Se ele é camelô e dono de loja estabelecida, vende pirata e oferece nota fiscal, sua ação é considerada legal. É sobre essa metamorfose que Machado (2004) se dedica, questionando a fronteira que separa o legal do ilegal, o formal do informal.

Assim, um fator que vai além dessa discussão é a questão da pirataria e dos produtos falsificados. Em todos os trabalhos estudados até aqui sobre o mercado camelô, essas discussões transitam frequentemente, como é possível evidenciar numa passagem do trabalho etnográfico de Quezada (2008, p. 23):

Novembro de 2002. Após cumprimentos desinteressados com alguns camelôs da esquina da Rua Paula Freitas com a Avenida N. Sra. de Copacabana, chamou-me a atenção uma das barraquinhas pelo ajuntamento de pessoas que aglomerava. Na banquinha de madeira, de aspecto improvisado, construída com ripas e pregos, um grupo de mulheres frenéticas manuseava o que parecia ser o trunfo do comércio de rua para aquele final de ano: as bolsas da marca Louis Vuitton. Sobre a banca estavam cinco ou seis diferentes modelos da bolsa, além de alguns exemplares de carteiras e agendas, que causavam furor entre as freguesas. Os comentários de "olha essa que linda", "eu quero essa", "nossa, elas parecem perfeitas", eram seguidos pelo abrir e fechar de zíperes e bolsos, do verificar da costura, do experimentar das peças, e finalmente a pergunta: quanto custa? Antônio, o responsável pela banca, anunciara a quantia exorbitante e surreal para os padrões do comércio de rua do bairro, e da cidade como um todo: R \$500,00. Diante do espanto geral, Antônio apressou-se em explicar as facilidades das condições de pagamento. Segundo ele, cheques eram bem vindos; caso a freguesa se decidisse pela mercadoria, o pagamento poderia ser feito em três parcelas com cheques pré-datados, sendo que na compra de três ou mais bolsas ele fazia abatimentos. Muitas mulheres mostraram-se interessadas, 
apesar de receosas em comprometer o orçamento principalmente naquele período de festas de final de ano. Antônio, então, distribuiu um cartão de contato onde se lia "Rei das Bolsas de Copa", seu nome e um número de celular.

A autora comenta que essas falsificações foram o furor de venda em 2002 no Rio de Janeiro, tanto que, em dezembro do mesmo ano, houve a apreensão de um contêiner com 9 mil bolsas Louis Vuitton falsificadas, que vieram de Hong Kong e seriam distribuídas em São Paulo e no Rio. 0 que mais chamava atenção das autoridades que apreenderam o contêiner, segundo a autora (2008), era a perfeição nas falsificações. Em tom de surpresa, a autora salienta que, Brasil e China, Hong Kong e Copacabana, conexões que, num primeiro momento, poderiam parecer presunçosas e surreais, agora forneciam subsídios para outra configuração de mundo.

Essa discussão mostra um panorama geral da atividade de camelô, assim como do circuito da camelotagem, como prefere chamar Rodrigues (2008), e também do circuito da falsificação e dos produtos "made in China", que abastecem o mercado brasileiro de falsificações, sendo os camelôs um dos grandes pivôs da difusão desses produtos. Além disso, foi possível detectar a ambiguidade nas ações dos camelôs, que giram em torno da formalidade e informalidade e também da legalidade e ilegalidade.

\section{Considerações finais: implicações entre atividade de camelô, cidade e território}

Esse percurso de discussão sobre a atividade de camelô foi necessário a fim de se detectar as possibilidades de articulação entre os conceitos de cidade, território e a atividade de camelô. Constatouse que o mercado camelô é uma atividade que se proliferou e disseminou no contexto das cidades, muitas vezes ligados à precariedade e à informalidade, além dos problemas estruturais na absorção de mão de obra. Seguindo a lógica da reestruturação produtiva, é possível detectar que tal mercado é uma realidade em muitas cidades brasileiras, o que torna difícil dizer que não há relações entre esse mercado e o desenvolvimento das cidades, sejam elas vistas como informacional (CASTELLS, 2000), como e-topias (MITCHELL, 2003) ou, ainda, como organizações sociais (MAC-ALLISTER, 2004) e cibercidades (LÉVY, 1999). Em cada um desses contextos é possível detectar o funcionamento do mercado camelô e a proliferação do consumidor em vários setores.

Por esse motivo, o objetivo neste ensaio foi analisar a atividade de camelô a partir das discussões e dos conceitos de cidade e território, procurando mostrar que muitas das manifestações urbanas escapam à lógica da reestruturação produtiva e também à ideia de cidade-conceito, que foi discutida no trabalho de Certeau (2008). Com isso, o mercado camelô surge como uma prática urbana, dadas as mudanças sociais, econômicas e estruturais que impulsionam (re)configurações constantes sobre as relações entre os indivíduos e sobre a dinâmica das ações realizadas no contexto urbano. Assim, Certeau (2008) diz que uma análise sobre as cidades não deve passar pela ideia de cidade-conceito ou cidade dual, pois essas são formas generalizáveis e universais de compreensão sobre as cidades. $\mathrm{Na}$ visão desse autor, é necessário visualizar e compreender a dinâmica das cidades a partir das "práticas urbanas", que são micros, pulsantes e que permitem detectar a diversidade e heterogeneidades das ações urbanas.

Diante de tais constatações, distanciar-se dessas concepções generalizantes de compreensão das cidades (cidade-conceito e cidade dual) permite retirar a atividade de camelô do complexo que vincula essa modalidade de mercado às referências já citadas de uma casta social marginalizada, de um trabalho precário e de um grupo que procura sobreviver na ilegalidade e na informalidade. Isso cria uma série de pressupostos que não condizem com a realidade e não estão submersos à lógica da cidade dual ou cidade-conceito. 0 mercado camelô possui centralidade, não no sentido de ter-se estabelecido no centro das cidades (em muitos casos), mas de ser um dos grandes disseminadores de produtos (legal ou ilegal, formal ou informal) que cria o sustentáculo para que a cidade dual se torne uma cidade híbrida. Esse mercado, de uma forma ou de outra, acaba "inserindo", permitindo a difusão de uma cidade informacional para além da fronteira, para além do que está dentro ou fora, para além de uma visão míope - que Machado (2004) discute muito bem em seu trabalho - daquilo que é legal ou ilegal, assim como daquilo que é formal ou informal. 
Por esse motivo a filiação ao projeto de Certeau (2008), que procura observar o contexto das cidades não como estruturas gerais ou como conceitos elaborados nos quais elas poderiam ser encaixadas, mas como práticas urbanas, diversificadas, multifacetadas, simbolicamente ricas. Tendo em vista essa constatação é que nas cidades há sempre a possibilidade de estudos diversos e de verificação dos seus aspectos peculiares. Isso fica evidente também no trabalho de Magnani (2002), o qual afirma que as cidades devem ser observadas, não somente pelos atores que as estruturam, como os detentores de capital, os empresários ou algo do tipo, mas também pelos seus moradores que, em suas múltiplas redes, formas de sociabilidade, estilos de vida, deslocamentos, conflitos etc., constituem elementos que dão vida às cidades.

Magnani (2002) salienta que as práticas urbanas, mesmo numa megacidade, impõem modificações na distribuição e forma dos seus espaços públicos, nas relações com o espaço privado, no papel dos espaços coletivos e nas diferentes maneiras que os seus agentes (moradores, visitantes, trabalhadores etc.) usam e se apropriam de cada uma dessas modalidades de relações espaciais. Do que mais Magnani (2002) pode estar falando ao elucidar as diferentes maneiras de condutas dos agentes integrantes das cidades, senão dos aspectos simbólicos e culturais que permeiam esses espaços? E quando Magnani (2002) diz que esses agentes usam e se apropriam de cada uma dessas modalidades de relações espaciais, do que mais ele pode estar falando senão dos aspectos territoriais?

Para transitar no entremeio a essas questões, o trabalho de Souza (2009) se torna importante. Sem dar continuidade à lógica das questões colocadas, mas com a intenção de alguma forma respondê-las, Souza (2009) apresenta uma discussão importante sobre o fato de o território ser material ou imaterial. Para esse autor, o substrato para o surgimento da ideia de território é o exercício do poder; por isso, um primeiro conceito dado é que o território é um espaço definido e delimitado por e a partir de relações de poder, o que concede ao território a materialidade de sua existência. Num segundo momento, Souza (2009) afirma que os territórios são, no fundo, antes relações sociais projetadas no espaço e que, desse modo, os eles são provenientes de relações de poder espacialmente delimitadas, operando sobre um substrato referencial.

Seguindo uma linha próxima às discussões de Certeau (2008), Souza (2009) ressalta que as fronteiras e os limites podem ser "invisíveis", o que implica o deslocamento dessas formas sem a alteração evidente na paisagem. Se o substrato material é importante para a existência dos territórios, a imaterialidade possui centralidade na dinâmica e produção desses territórios, o que confere significados e o substrato referencial para a própria existência das relações de poder. Na perspectiva traçada por Souza (2009), o poder é uma relação social (ou mesmo uma dimensão dessa relação) e o território é a expressão espacial disso.

Segundo esse autor, se durante muitos anos a temática que dominou os estudos sobre território esteve vinculada à ideia de Estado-nação, o que permitiu verificar as fronteiras estatais como fixas, assim como as ordens de grandeza na análise das divisões estatais, nos últimos anos os geógrafos têm observado que, mesmo as fronteiras estatais, quando se aproximam da longue durée, apresentam mudanças, fluidez e transformações evidentes. Por esse motivo, salienta Souza (1995), o território pode vir a ser subdividido, repartido, pulverizado entre facções rivais, como no caso de Cartago depois da última guerra Púnica, onde ambiente construído e território foram varridos do mapa. É a partir dessas perspectivas que Souza (2009) fala em territórios e pulveriza a ideia de território para o contexto do "mundo da vida", falando sobre o que chamou, em outro trabalho, de "nanoterritório" (SOUZA, 2006).

Para Souza (2006), esse nanoterritório está vinculado ao quotidiano dos indivíduos e grupos sociais, em que as fronteiras englobam uma rua ou um trecho de rua, um prédio ocupado por sem-teto, uma prisão, parcela da arquibancada de um estádio de futebol e, por que não, um mercado camelô. Na visão do autor, esse nanoterritório nos leva a experimentar, em matéria de campos de força do poder espacializado, realidades espaçotemporais bem diferentes da aparente fixidez das fronteiras estatais. É deste ponto de vista que os territórios assumem uma escala, por excelência, dos oprimidos e de suas táticas, com suas resistências quotidianas inscritas no espaço ou expressas espacialmente. Examinando as práticas sociais, salienta Souza (2009), é que se torna possível observar que tais práticas são, quase 
sempre, práticas espaciais e, consequentemente, ações de territorialização. Essas ações se concretizam em escala temporal de curta ou curtíssima duração e são sempre marcadas pela instabilidade.

Tal discussão de Souza (2009) possibilita reflexões interessantes sobre as novas designações da ideia de cidade. Se a tendência é verificar as cidades como e-topias, como cibercidades, como cidades informacionais e como cidades globais, isso se deve ao fato de que a lógica instituída da permanência e da fixação já não transita mais sobre as concepções de cidade. De que a ideia de espaços delimitados e divididos segundo lógicas internas já não se refere mais às transformações evidentes na estrutura das cidades. De que fronteiras imutáveis já não se tornam um objeto de constatação nem mesmo pelos geógrafos. Mas o que ocorreu? Ocorreu que a coisificação das cidades e dos territórios há muito tem sido questionada, seja pelos sociólogos urbanos, seja pelos geógrafos.

Se nas discussões sobre as cidades e os territórios a materialidade possuía a centralidade necessária no processo de análise, nos últimos anos a tendência a verificar a imaterialidade nestas mesmas discussões tem sido alvo de intensos debates. Por esse motivo, para Souza (2009) é necessário "descoisificar" o território, o que não quer dizer negligenciar a parte material ou paisagística dos espaços, mas de enriquecer o arsenal conceitual para verificar a imaterialidade de tais manifestações, o que impulsiona a lógica de entendimento, até mesmo dos ambientes virtuais, assim como da inversão da dinâmica espacial ditada pelo predomínio das relações temporais.

0 entendimento dessas redes de significados é que possibilitaria verificar maneiras diversas de conceber os atributos materiais e imateriais produzidos e utilizados, que podem ser detectados de forma geral, visível em vários contextos e estudos - como no caso do estudo de Machado (2004) e Rodrigues (2008) em suas idas a Ciudad del Este mas também em espaços específicos, pois as formas de conceber os atributos materiais e imateriais produzidos e utilizados, por exemplo, em Porto Alegre, RS (MACHADO, 2004), chega a ser completamente diferente daqueles compartilhados em Marilia, SP, e Presidente Prudente, SP (RODRIGUES, 2008), com aqueles de Pelotas, RS (GOULARTE, 2008), e também do Rio de Janeiro, RJ (QUEZADA, 2008). Essas peculiaridades é que abrem a possibilidade de um estudo sobre as práticas urbanas.
Nestas práticas há a filiação dos aspectos simbólicos, como mitos, ritos, crenças, ideias, leis, regras e normas, ao mercado camelô em si e às peculiaridades regionais, da sua história, da forma como esse mercado foi constituído, da estrutura e existência sobre esse mercado, entre tantas outras peculiaridades. São esses aspectos simbólicos que produzem papéis diferenciados aos sujeitos integrantes, com nomes específicos e peculiares em cada região. Como exemplo, fica o caso dos ambulantes de Porto Alegre que, de acordo com o trabalho de Machado (2004), são chamados de "caixinhas", sendo que essa categoria sequer aparece nos trabalhos de Quezada (2008) e Rodrigues (2008).

Esses papéis e valores simbólicos concedidos a eles é que permitiriam verificar as disposições desiguais de onde as relações de poder estariam manifestas, como no caso do embate diferenciado em cada região com o poder público e os comerciantes locais. A partir dessas disposições desiguais se torna possível entender o limiar entre o formal e o informal, entre o legal e o ilegal, entre as possibilidades de um mercado e suas limitações etc.

Apesar dos estudos e das constatações evidentes nas discussões desenvolvidas até aqui, a produção de novas temáticas ou de outros olhares para essa atividade é de suma importância na reflexão de seus meandros e nas possibilidades sempre abertas de compreensão e entendimento deste mercado.

\section{Referências}

CASTELLS, M. A. A sociedade em rede. In: CASTELLS, M. A. A era da informação: economia, sociedade e cultura - vol. I. Trad. Roneide Venancio Majer. São Paulo: Paz e Terra, 1973.

CASTELLS, M. A. La ciudad informacional: tecnologías de la información, reestructuración económica y el proceso urbano-regional. Madrid: Alianza, 1995.

CASTELLS, M. A. Questão urbana. São Paulo: Paz e Terra, 2000.

CERTEAU, M. D. A invenção do cotidiano: a arte de fazer. 14 ed. Petrópolis: Vozes, 2008.

GEORGE, P. Sociologia e geografia. Rio de Janeiro: Forence, 1969. 
GOULARTE, C. C. Cotidiano, identidade e memória: narrativas de camelôs em Pelotas-RS. 2008. 106 f. Dissertação (Mestrado em Ciências Sociais) - Universidade Federal de Pelotas, Pelotas, 2008.

HARVEY, D. Condição pós-moderna. São Paulo: Edições Loyola, 1992.

HARVEY, D. A produção capitalista do espaço. São Paulo: Annablume, 2005.

HOBBES, T. Leviatã. São Paulo: Nova Cultural, 1997.

LÉVY, P. Cibercultura. São Paulo: Editora 34, 1999.

LOPES, V. L. S. Meio de vida: as experiências de sobrevivência e luta dos trabalhadores ambulantes e feirantes em Fortaleza entre o final da década de 1960 e início de 1970. 2004. 207 f. Dissertação (Mestrado em História Social) - Universidade Federal do Ceará, Fortaleza, 2004.

MAC-ALLISTER, M. A cidade no campo dos estudos organizacionais. Organizações \& Sociedade, Salvador, v. 11, p. 171-181, 2004.

MACHADO, R. P. A garantia soy yo: etnografia das práticas comerciais entre camelôs e sacoleiros nas cidades de Porto Alegre (Brasil) e Ciudad del Este (Paraguai). 2004. $143 \mathrm{f}$. Dissertação (Mestrado em Antropologia Social) - Universidade Federal do Rio Grande do Sul, Porto Alegre, 2004.

MAGNANI, J. G. C. De perto e de dentro: notas para uma etnografia urbana. Revista Brasileira de Ciências Sociais, v. 17, n. 49, junho, 2002.

MITCHELL, W. J. e-topía. Barcelona: Gustavo Gili, 2003.

QUEZADA, D. I. C. Ser ou Estar? Eis o dilema: o cotidiano de ambigüidades dos camelôs de Copacabana. 2008. 107 f. Dissertação (Mestrado em Sociologia e Antropologia) Universidade Federal do Rio de Janeiro, Rio de Janeiro, 2008.
RODRIGUES, I. D. A dinâmica geográfica da camelotagem: a territorialidade do trabalho precarizado. 2008. 186 f. Dissertação (Mestrado em Geografia) - Universidade Estadual Paulista, Presidente Prudente, 2008.

SANT’ANNA, M. J. G. A concepção de cidade em diferentes matrizes teóricas das ciências sociais. Revista Rio de Janeiro, n. 9, p. 91-99, jan./abr. 2003.

SASSEN, S. As cidades na economia mundial. Trad. Carlos Eugênio Marcondes de Moura. São Paulo: Studio Nobel, 1998.

SOLÀ-MORALES, I. Territórios. Barcelona: Gustavo Gili, 2002.

SOUZA, M. L. 0 território: sobre espaço e poder, autonomia e desenvolvimento. In: CASTRO, I. E. (Org.). Geografia: conceitos e temas. Rio de Janeiro: Bertrand Brasil, 1995.

SOUZA, M. L. A prisão e a ágora. Reflexões sobre a democratização do planejamento e da gestão das cidades. Rio de Janeiro: Bertrand Brasil, 2006.

SOUZA, M. L. Território da divergência (e da confusão): em torno das imprecisas fronteiras de um conceito fundamental. In: SAQUET, M. A.; SPOSITO, E. S. (Org.). Territórios e territorialidades: teorias, processos e conflitos. São Paulo: Expressão Popular, 2009.

WEBER, M. 0 fenômeno urbano: conceito e categorias de cidade. Rio de Janeiro: Zahar, 1973.

Recebido: 24/09/2011

Received: 09/24/2011

Aprovado: 23/03/2012

Approved: 03/23/2012 